\title{
Peru: Tell clients how to use their chosen method
}

Frontiers in Reproductive Health

Follow this and additional works at: https://knowledgecommons.popcouncil.org/departments_sbsr-rh

Part of the International Public Health Commons, and the Women's Health Commons How does access to this work benefit you? Let us know!

\section{Recommended Citation}

"Peru: Tell clients how to use their chosen method," FRONTIERS OR Summary. Washington, DC: Population Council, 2000. 
Peru

Quality of Care

OR Summary 13

\section{Tell Clients How to Use Their Chosen Method}

\author{
Family planning providers in Peru need to focus more closely on giving \\ clients relevant information on their chosen method and asking key \\ questions in order to make the most efficient use of the time available for \\ client counseling.
}

\section{Background}

In 1998 the Peruvian Ministry of Health (MOH) issued quality of care norms to ensure that family planning providers respond to their clients' reproductive health care needs and goals. In mid-1999 the Population Council collaborated with the $\mathrm{MOH}$ on a study to determine whether the length of counseling sessions affects the amount of information provided to the client.

Using Lot Quality Assurance Sampling, the study focused on 19 health centers in 10 urban areas, drawn from a national sample of 172 facilities. Six simulated clients (women posing as clients) made a total of 114 visits to the 19 health centers during JuneJuly 1999. Each simulated client was trained to say that she wanted to switch from the rhythm method to a more effective method. After counseling, she chose the injectable Depo-Provera but stated that she wished to consult her husband before beginning use.

To assess the quality of counseling, the simulated clients completed a checklist after each visit, indicating what information had been given to them. The checklist consisted of 46 items reflecting optimal information exchange. It covered: questions to identify factors relevant to contraceptive options; information on available contraceptive methods; questions to screen for contraindications to injectable use; information about injectable use, side effects and warning signs; use of barrier methods for temporary protection against pregnancy; and follow-up instructions.

\section{Findings}

- Providers conveyed more information during sessions lasting nine minutes or longer, compared with shorter sessions. During the sessions lasting 9-14 minutes, providers covered 42 percent of the 46 items on the information exchange checklist, compared with 30 percent of the checklist items during shorter sessions of eight minutes or less. However, information exchange improved only slightly during counseling sessions lasting 15-45 minutes.

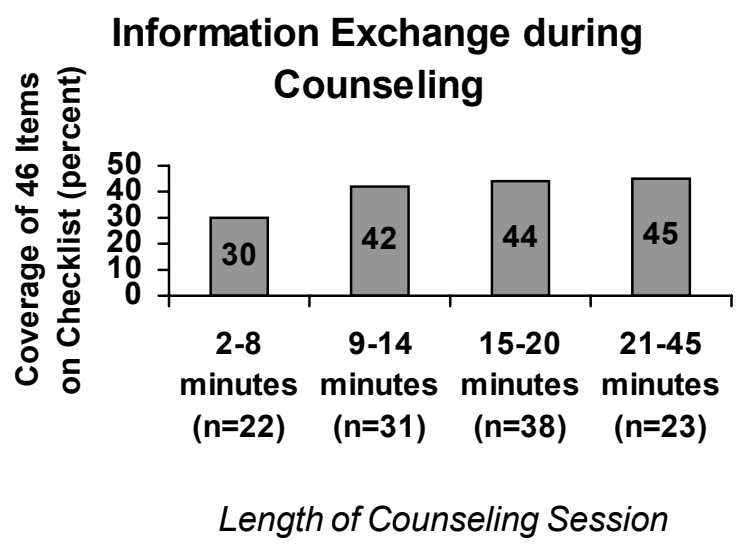


- Longer counseling sessions did not lead to more information exchange because the providers spent the extra time giving clients more details about methods they were not planning to use, rather than giving them essential information on use of their chosen method and screening for contraindications. In fewer than 20 percent of the visits, providers asked about vaginal bleeding, discussed breast cancer, advised interim use of barrier methods, or asked whether the client understood.

- Nevertheless, providers are meeting many quality of care goals. In more than four in five counseling sessions, providers asked standard questions needed to assess appropriate contraceptive options, discussed four or more contraceptive methods, and asked the client to make a choice of methods.

- Providers involved in the study welcomed the feedback regarding the quality of their counseling. They cited time constraints as the major cause of insufficient counseling. Some visits were clearly too short, but the average visit lasted 15 minutes, which should have been sufficient to cover key information. Researchers concluded that providers could have used their counseling time more efficiently. Also, they missed opportunities to provide client-centered treatment by asking questions to ascertain each client's situation and needs.

\section{Policy Implications}

- The MOH should test an alternative model for client counseling in order to help providers to give more effective, client-centered family planning counseling. This model consists of five steps:

1. A warm welcome;

2. A client-centered diagnosis that identifies a subset of appropriate family planning methods;

3. Provision of appropriate, personalized information on appropriate methods, leading to choice of a single method;

4. Screening for contraindications, education on use of the method chosen, and instructions for follow-up; and

5. Feedback to ensure understanding and appropriate follow-up.

This model should stress the provider's role after a contraceptive method has been chosen, including screening for contraindications, giving instructions on correct use, and discussing side effects and warning signs. The MOH should develop job aids to help providers implement this model and should undertake operations research to assess its value.

León, Federico R. et al., 1999. Counseling Sessions Length and Amount of Information Exchange in Peruvian Clinics. For more information, contact: Population Council, Av. San Borja Sur 676, Lima 43, Peru. Tel. 511-475-0275; Fax: 511-475-0675; E-mail:

pclima@amauta.rcp.net.pe or contact: Population Council, Escondida 110, Villa Coyoacán, 04000, Mexico, D.F. Mexico. Tel.52-5659-8537; Fax: 52-5554-1226; E-mail: disemina@popcouncil.org.mx.

This project was conducted with support from the U.S. AGENCY FOR INTERNATIONAL DEVELOPMENT under Cooperative Agreement Number HRN-A-00-98-00012-00. 